Article

\title{
One Step Ahead of Active Shooters: Are Our University Buildings Ready?
}

\author{
Kristy Kellom and Linda Nubani * \\ School of Planning, Design \& Construction, Michigan State University, 552 W Circle Dr, East Lansing, MI 48824, \\ USA; kellomk@msu.edu \\ * Correspondence: nubanili@msu.edu; Tel.: +1-(517)-432-2330
}

Received: 3 September 2018; Accepted: 3 December 2018; Published: 5 December 2018

\begin{abstract}
Active shooter incidents typically transpire quickly. Research reveals that 70 percent of active shooter incidents end in less than $5 \mathrm{~min}$, and that a majority of incidents are over before law enforcement arrive on scene. This study analyzes the level of preparedness among a sample of faculty members on executing "Run, Hide, Fight" in two university buildings that range in layout complexity. It also analyzes design challenges impacting response time for a sample of police officers. A visibility graph analysis (VGA), a new architectural based simulation tactic, was conducted to measure visual exposure and access, the legibility of layouts, and the ease of wayfinding within these two buildings. The findings showed that VGA measures explained the perceived level of preparedness among faculty members, and the importance of visibility to the police when they clear the building room by room. These measures may have the ability to identify the risk of exposure to shooters while attempting to run or hide, and to identify potential hidden spots in any floor plan.
\end{abstract}

Keywords: active shooter prevention; simulation; hotspot mapping; visibility; university shootings

\section{Introduction}

\subsection{Active Shooter Incidents}

According to the Federal Bureau of Investigation (FBI) reports of active shooter incidents in the United States between 2000 and 2015, the United States has experienced 200 incidents that resulted in 1274 casualties [1,2]. Educational environments account for 24.4 percent of these incidents [1,2].

\subsection{Run, Hide, Fight}

In response to recent active violence incidents, universities have increased employee safety training measures. Many departments encourage an approach similar to the Federally-endorsed Run, Hide, Fight concept promoted by the Department of Homeland Security (DHS) in preparation for active violence incidents, where trainees are instructed first to "run if you can", then "hide if you must", and finally to "fight if you have to" [3]. Approximately 60 percent of active shooter incidents end before the police have an opportunity to stop the threat, creating high risk situations [1]. This means it is critical that occupants are prepared to quickly evaluate surroundings and choose the best option. However, preparing every civilian to effectively execute a comprehensive emergency plan, within minutes, is a daunting task. Additionally, very little research has been conducted on the effectiveness of such training programs [4]. But, for those who have been trained, what happens when the building design does not support the occupants' trained response? The questions may be raised: Can the layout of a building play an important role in effectively preventing or deterring a threat from materializing? Is the layout legible enough for the occupants to make their decisions to run or hide? Does the layout 
give the police visual control over their surroundings while clearing the building and looking for the shooter? Does space create a visual opportunity for an active shooter to carry his act?

While local police are responding with increased training to reduce response time, health professionals are addressing the motivation to act by improving prevention efforts through mental health resources, and administrators are improving occupant preparedness through the implementation and training of emergency action plans, there is limited research on the role of the building in relation to the act of crime in active shooter incidents [4,5]. Based on the authors' review of the literature, studies have not been conducted regarding the relationship between the physical building and an offender's ability to carry out such an attack, nor in measuring spatial decisions made by first responders. There is a critical need for continued research to determine the effectiveness of risk mitigation and prevention strategies.

Many agencies have communicated a need for further research to better prepare communities and to protect schools from active shooter threats [6]. Downs [7] discussed the need to create heightened security measures that offer a safe learning environment, while balancing safety and education. In response to the Virginia Tech mass public shooting of 2007, the CLERY Act was amended in 2008 to include the Higher Education Opportunity Act. This act expanded emergency response and notification provisions, requiring institutions to implement a campus emergency response plan [8]. The InterAgency Board [9] recommended emergency response agency training, active bystander training, and continued research and data analysis, as well as the development of preparedness activities for active shooter events. Additional research to explore factors that are related to the crime setting and leading up to an active shooter event, such as event-level decisions and the role of planning, may help to prevent future events or mitigate impact, thereby saving lives $[8,10]$. Ultimately, conducting building-level research and establishing guidelines that design practitioners can immediately apply might narrow the knowledge gap between researchers and practitioners $[10,11]$. Therefore, the aim of this pilot study is to start the conversation around the role of architectural layouts in facilitating or hindering the Run, Hide, Fight training of building occupants in university buildings, as well as facilitating or hindering the tactful response of police as they clear the building while looking for the shooter.

\subsection{Education Environments}

Though existing reports catalog all school-related incidents together as Education Environments, recent studies dissect this category further, describing Pre-K-12 school incidents separately from institutions of higher education incidents [1]. This pilot study is part of a larger ongoing study that focuses on incidents at college and university environments due to the uniquely open access of most higher education campuses.

In contrast to the layout of most Pre-K-12 schools, in higher education, most campuses are comprised of a variety of building types and functions, including educational, work place, residential, retail, hospitality, and more. The open access nature of university campuses leaves occupants particularly more vulnerable [8]. Executing Run, Hide, Fight may be possible and effective in some spaces, for instance, in personal or administrative offices. However, in a review of the impact at Virginia Tech, it may be noted that all of the casualties were students or faculty, primarily in teaching spaces, and not including campus visitors. Further clarification of the Hide command instructs occupants to lock or barricade doors, turn off lights, and take cover behind furniture [3]. However, it may be noted that in analyzing primary teaching spaces at one university, hiding may not be physically possible due to design constraints within the classrooms. In these teaching spaces, for example, most doors are not lockable, many doors swing out into the interior corridor to comply with fire code regulations (difficult to barricade), many utilize open furniture (hinders ability to self-conceal), and many incorporate doors with inset glass panels or full curtain walls with floor to ceiling windows openly visible from interior corridors. Even with the light fixtures turned off, light from the corridor or daylight from exterior windows may still illuminate the space. Additionally, architectural layout may be responsible for 
creating spaces that are visually exposed for the occupants from multiple locations. Picture a classroom bounded by three hallways with multiple exits (fire code) and multiple windows along its walls. In addition to visual exposure, the layout of the building may be too complex, making wayfinding a bit more challenging for the occupants to make cognitive decisions on figuring out the best alternatives to the nearest exits. Similarly, when police arrive to the scene, it is important for them to be able to have visual control of the building so they are not caught off guard by the shooter in the event he or she was hiding. These physical limitations would leave the occupants exposed and at higher risk during an active shooter incident. Furthermore, recent public mass shooting incidents in educational facilities, for instance, Virginia Tech and Sandy Hook Elementary, demonstrate that multiple people hiding in a room with little or no cover or concealment may actually create an opportunity for the shooter to inflict higher rates of casualty with fewer rounds fired [3].

This paper reviews the literature, including visibility in buildings in relation to visual access and visual exposure, wayfinding, and legibility of architectural layouts, prior studies on active shooting incidents, the psychology of occupant preparedness, the role of the building in occupant preparedness, and finally, how police navigate buildings in response. The literature review is followed by a section on the authors' methodology, and statistical findings from two surveys, as well as a visibility graph analysis.

\section{Literature Review}

\subsection{Measuring Visibility in Identifying Hotspots in Buildings}

There is a growing body of literature that calls for the importance of the attributes of places in facilitating crimes like burglaries. Steenbeek and Weisburd [12] found that most of the crime in Hague over eight years were explained by looking at the street segment as the unit of analysis. This is to suggest that it is possible for city planning to be responsible for giving certain attributes to these street segments that provide opportunities for criminals to commit their crimes. These findings follow closely the routine activity theory by Cohen and Felson in the 1970s. The theory suggests that a crime is more likely to happen if a likely offender, a suitable target, and absence of guardianship come together in time and space [13].

Newman's [14] theory of natural surveillance, which suggested the significance of visible attributes of a space in relation to crime, offered a new criminological perspective in the connection between crime and place. His theory was preceded by Jacobs' [15] concept of "eyes on the street" that has a significant impact on crime. Over the years, some researchers have attempted to test the theories of Newman and Jacobs for various crime types, such as bank robberies, burglaries, and vehicle theft [16-18]. More recently, due to advancement in technology, some researchers have developed measures to test these visibility factors [18]. One of the techniques used by the space syntax group of theories, referred to as isovist-based analysis, involves calculating parameters related to visibility in both indoor and outdoor environments. Those parameters include area of visibility, skewness of visibility, and perimeter of visibility. Some of these parameters can been used to calculate "visual access" and "visual exposure" as defined by Archae [17], where visual access is the degree to which one can monitor his or her spatial surroundings by sight, and visual exposure is the degree to which one may be monitored from other locations. For example, the ability to have a good overview of a classroom from a certain location in the hallway is what Archae refers to as visual access. When people walk through space, different visual fields unfold as their vantage points change. Visual fields could be maximized if one strategically select or move within vantage points with high visual fields. When multiple vantage points overlap in their visual fields, one may feel visually exposed from within the overlap. One such example is a classroom with multiple entries or glass windows.

There is little empirical research found regarding the relationship between spatial arrangement and active shooter criminal behavior inside buildings. However, following the routine activity theory, can space syntax be used to examine these relationships in a building context-specifically in an active 
shooting event? Various space syntax techniques were used to examine criminal's preference for crime targets within urban settings [18]. Nubani [18] found that axial line analysis that measures accessibility levels of streets segments in the city explained certain types of crimes (namely larceny, breaking and entering and motor vehicle theft). In the same study, visibility graph analysis was able to explain where exactly along these street segments would these types of crimes occur. Nubani [18,19], however, points to the importance of integrating sociodemographic variables such as levels of home ownership and income in explaining criminals' preferences for crime targets.

\subsection{Building Layouts, Wayfinding and Legibility}

In addition to the importance of visual access and exposure in monitoring others and being monitored by others, the amount of visual fields as one moves from one location to a certain destination is an important measure of wayfinding. Early work by Kevin Lynch provided a major contribution to our understanding of human cognition and wayfinding behavior [20]. Within the context of building interiors, wayfinding could be measured by the legibility of its floor plan [21,22]. Lynch argues that legibility of architecture is influenced by the organization of the environment. If the arrangement of objects within the space (e.g., walls and hallways) is legible and coherent, not only will wayfinding become simpler, but constructing a cognitive map of the surroundings becomes easier on the building occupant. In other words, it is possible for a building occupant to mentally visualize the layout of the building without the need to access its floor plans. As explained in the methods section, isovist based techniques can also be used to measure legibility of building layouts and ease of wayfinding.

\subsection{Prior Studies on Active Shootings}

Various methodologies have been conducted in the data collection related to the person responsible for an active shooter event. A case study collection as well as qualitative observations were compiled by a collaboration of federal agencies [8]. Other researchers gathered data from 20 reports to analyze patterns, thus collecting recommendations for improved security responses of colleges and universities such as emergency response plans, training, and mass notification systems [23]. The New York City Police Department (NYPD) conducted a large-scale qualitative analysis, from open-access sources, of 324 active shooter incidents around the world between the years 1966 and 2012, followed by some quantitative analysis of a sub-group of incidents in the U.S. with one or more reported casualties [24]. A five-stage sequential model was established to explain the effect of several criminological theories, including routine activities theory, by which stage 4, the "planning stage" confirms the premeditation of these targeted events [25]. A rational choice perspective and crime script analysis study were conducted to classify why these events occurred, and to examine event-level characteristics, in an effort to gain insight for future prevention measures [10]. The most current comprehensive study at the time of this publication is a qualitative analysis of every major active shooter incident in the United States from 2000 to 2013, which included descriptions of 160 events and statistical details regarding each location category [1]. The researchers compiled and analyzed data using FBI records, police reports and other open sources.

\subsection{The Role of the Building in Active Shooter Planning and Implementation}

Though available analyses suggest that most incidents are planned methodically in advance, few investigations mention any physical characteristics of the location or building selected. There is some indication that autogenic or ideological-based shooters, those not targeting a specific person, may choose more highly populated locations [5]. Most chose places they had authorized access to at the time of the incident [10], which calls for the need to acknowledge this issue in target hardening strategies. Additionally, evidence shows that some considered attacking other locations first, but they ultimately chose the location with the least amount of security, indicating the important role that opportunity may play in location selection $[10,26]$. Though some actors remain mobile, other incidents indicate that the actor selected "a location for tactical advantage, such as a high, protected location" [5] 
(p. 9). This distinction implies some spatial decision-making by the actor, indicating that a shooter's ability to see without being seen may be considered a high priority in the planning stages. Particularly, a shooter that is intent on killing a large number of people, who spends more time planning, may consider visual exposure in the location selection.

A recent example from the tragic Las Vegas shooting shows how the active shooter left behind a hand-written note with calculations of appropriate angles and distances that provided him enough visual exposure to carry out his act [27]. Why wait? Perhaps the time is now to conduct visibility analyses on public spaces, especially prior to large or mega-scale public events, followed by improved security measures. Could preventative visibility analysis help prevent mass public shootings? The authors of this paper propose to further investigate the role that visibility attributes may play in prevention and response time.

\subsection{Psychology of Occupant Preparedness}

Considering the time gap between the average duration of an active shooter event and police response time, potential victims may be without the help of law enforcement at the beginning of or possibly throughout an attack. It is highly encouraged to train civilians who might not otherwise be prepared to remain calm in life-threatening situations, such as in the Avoid, Deny, Defend method taught at ALERRT, which is research-based active shooter response training for law enforcement and communities at Texas State University [5]. According to the research, many active shooters were interrupted when potential victims took action instead of freezing in denial.

There is a rise in crafting preparation procedures and implementing training tools within schools and universities against active shooters. Although these types of trainings promise to increase preparedness among faculty, students and staff, an examination of its effectiveness on civilians is still lacking. One study that suggested some effectiveness in taking action was an analysis of the incident at Virginia Tech [5]. This report noted that 92 percent of the people in a room were shot when no actions were taken to stop the shooter, but no one was shot in a room where students executed the Deny action by locking and barricading the door.

\subsection{The Role of the Building in Occupant Preparedness}

As discussed earlier, many facilities are not designed to foster effective execution of the most commonly implemented training methods, such as Run, Hide, Fight, or Avoid, Deny, Defend. While Hide or Deny instructs occupants to lock or barricade doors to prevent the shooter from entering the room, in many higher education teaching spaces, doors may not have locks, and may swing out to the corridor to comply with fire codes. These spaces cannot easily be barricaded. How physically able are the building occupants to execute these trained response procedures? Do architectural attributes or design features promote safety in a building or hinder trained response efforts? How often do occupants consider these questions and formulate potential plans in each space they occupy?

\subsection{The Role of Design in Police Response Time}

Over the last three decades, agency response to active violence incidents has changed significantly in philosophy, methods, frequency, and scope. Understanding how police move through a building and make spatial decisions during an active shooter incident is relevant to the author's research questions. This literature review revealed limited academic sources regarding consistent or standardized police response methods, measured response time, or training implementation. However, police trade articles offer supplementary insight into continually developing active shooter response tactics. It may be noted from an analysis of the available literature [28] that law enforcement agencies tend to focus primarily on reactionary methods, as discussed throughout this chapter, and they may have less available resources to invest in passive prevention or deterrent efforts. 


\subsection{Measuring Spatial Movement and Time}

Two issues were highlighted in the literature: spatial movement and time. First, in the Critical Issues in Policing Seminar at the Active Shooter Conference in Washington D.C, experts from the Police Executive Research Forum (PERF) advised that if an active shooter event occurs in a school, a School Resource Officer should be part of the contact team or utilized as a coordinator to guide the contact teams, due to their familiarity with the building [5]. This leads to the question of whether familiarizing all officers with the ability to read floor plans as well as layouts of buildings within their jurisdiction could also help reduce response times?

Secondly, time is more of an issue in this situation than any other. As Murgado points out: "the time is out before you've even had a chance to respond" [29]. Pignatelli [30] mentions an Active Deadly Force Training lesson plan which provided a detailed account of training tactics related to dynamic entries, hallway movements, room and stairwell approaches, as officers in teams of two or three enter and move through a building to search for an active shooter. Stairwells, visual approach, visibility, and access control may play a significant role in active shooter incidents. Though Hyderkhan's [31] manual does provide diagramed formation methods, as well as stairwell approaches, there is not much documentation on these spatial considerations. As will be described in the next section, the authors of this pilot study are interested in measuring visibility.

\section{Methods}

The primary objective of this pilot study is to measure whether buildings create opportunities to execute Run, Hide, Fight in two university buildings at a U.S. institution. Because of advancements in computer technology, it is now possible to measure the visibility and legibility of building layouts mathematically using space syntax techniques [32]. Space syntax is a group of theories that look at the social use of space [32]. In her study, Nubani [18,33] analyzed visibility through the use of one space syntax technique known as Isovist-based visibility graph analysis (also known as VGA).

In this pilot study, the authors used visibility graph analysis (VGA) to objectively measure the impact of architectural layouts on visibility (visual access and visual exposure) and compared those measures to perceptions from two different groups as explained in the next section. The study was conducted on two university buildings, referred to in this article as Building A and Building B. Two hypotheses could be formed here: First, certain architectural layouts and design features that are responsible for creating certain visual fields in the building play a critical role in improving perception of preparedness; and second, ease of wayfinding impacts perceived ability to execute Run, Hide, Fight.

\subsection{Surveys}

\subsubsection{Survey One}

The first survey to police officers from six agencies was framed to collect two sets of data. First, information was collected about current procedures followed by first responders in active shooter training. These questions were addressed to establish the general knowledge of current first responder training tactics. Second, inquiry was made about the perception that first responders on the impact architectural features and awareness may have on response time. Specifically, the police perception of whether accessing building plans ahead of time might improve response time in confining the situation. Active duty police officers who have participated in active shooter response training were selected for this survey. At the time of this study, no comparable survey questions were established. Nine responses were received in total. The six agencies represented three different states and two federal jurisdictions.

\subsubsection{Survey Two}

The purpose of the second survey was to collect data about the faculty perception of preparedness for an active shooter incident in teaching spaces. Teaching spaces have variations in architectural 
characteristics and layout that may impact both perception and actual reaction in an active shooter incident (see Figure 1). Faculty members with teaching appointments (40 total: 20 male and 20 female) from a university in the U.S. were invited to participate via electronic mail. Survey questions attempt to assess the current level of training faculty receive, the confidence felt post-training, as well as the perceived feasibility of executing the Run, Hide, Fight trained response in adequate time when comparing two buildings with different architectural features. The first building, referred to in this article as Building A, represents a more complex layout, and less familiarity to participants. The second building, referred to as Building B represents a simpler layout, and increased familiarity to participants. At the time of this study, no comparable survey questions were established.

Of these 40 faculty members, one member declined to participate, and 22 members (55\%) completed the survey. The participants were 11 males and 11 females, between the ages of 35 and 64, $53 \%$ of whom indicated that they hold at least one degree in a design discipline. Twenty participants indicated some familiarity with Building A, while two indicated no familiarity. All of the participants indicated high familiarity with Building $\mathrm{B}$.

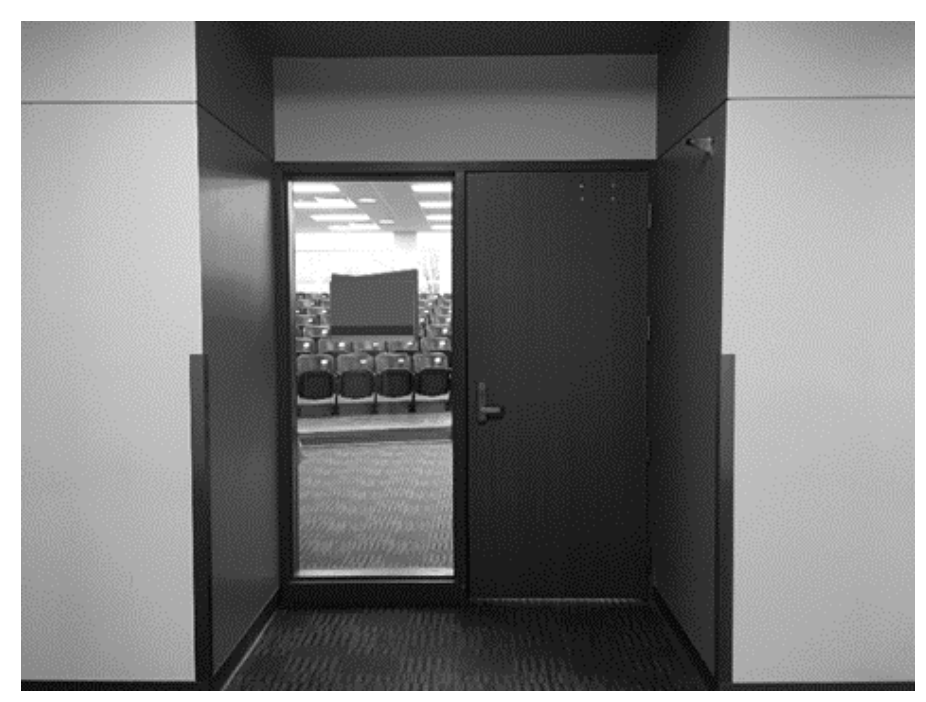

Figure 1. Shows a classroom door with a glass inset.

\subsection{Isovist-based Visibility Graph Analysis}

The campus buildings selected offer comparable space functions, including academic classroom spaces, conference rooms, and offices. However, the buildings range in the perceived level of floor plan complexity and architectural features, one being a simple linear layout, and one more complex layout including an atrium. Floor plans of these two buildings were obtained. Using Depthmap software developed by Turner et al. [34], a grid was created on both plans, with one foot spacing to capture more details of people walking on foot. The software has an algorithm that produces results while taking into consideration buildings with different sizes. Building A generated a total of 73,905 isovist grid points, while Building B generated a total of 14,360 isovist points. As briefly explained in the literature, an isovist is a point generated in a space with a polygon created 360 degrees around that point. This polygon represents the amount of visibility available from that point in space. Generating polygons allows measures such as the area and perimeter to be computed. In this study, all walls and above-eye level objects (e.g., bookcase, pillars) were computed as obstacles. Glazing (glass) and windows were programmed as clear openings, since visibility impacts spatial decisions made by active shooters and police responding to the scene (see Figure 2). In this pilot study, the authors used the following four visibility measures:

- Isovist area: The total amount of visibility in square feet is generated at each grid point within the building. 
- Integration: This measure represents the depth of an isovist point within the building. Highly integrated points are characterized by enjoying high accessibility from anywhere within the building. Literature showed that highly integrated spaces were associated with (1) attracting burglars in an urban environment [35] and (2) attracting strangers in a building [36].

- Connectivity: This measure represents the number of isovist polygons overlapping with the visual field at a certain point. Highly connected isovist points are those that enjoy high visibility when a person walks one step away or two steps away (in this study, one step equals one foot).

- Intelligibility: This measure is the ratio of connectivity to integration. Intelligibility was found to be associated with chances of encounter in office environments [33]. The values produced are between 0 and 1. Values closer to 1 represent highly intelligible floor plans. Multiple studies also showed how highly intelligible floor plans were associated with easy wayfinding [21,22].

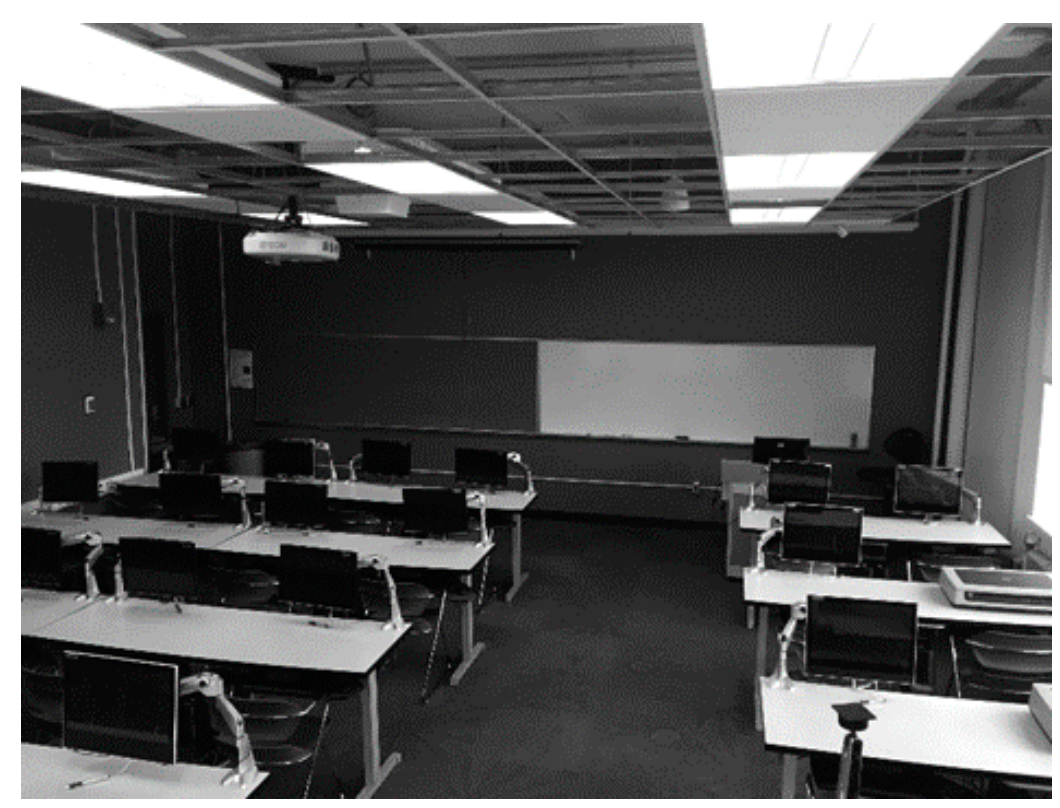

Figure 2. A sample of a classroom layout.

\subsubsection{Finding 1}

Figures 3 and 4 show the VGA output of the measure "isovist area" for Building A and Building B. The output ranges in color to give instant visual or feedback to the reader to see how the building works. White represents places with high visual exposures, and dark grey represent places with the least visual exposure in the plan. The two plans show distinct differences in terms of both the percentage of areas with high visual fields, and their distribution.

A careful examination of the two buildings show an instant visual of the places with high visual exposures. Most of the spaces within the floor plan of Building A enjoy high visual fields. Table 1 shows that the average visual area for Building $\mathrm{A}$ is close to 2500 square feet, while the average visual area for Building B is about 460 square feet. On the other hand, a careful examination of the floor plan of Building B shows how the junction between the hallways is the only area with the highest visual field. The area of the isovists decrease in size within this floor plan in an organized order where public spaces such as the hallways have the highest visibility, semi-public areas such as the reception area of a suite of offices have less visual areas, and private offices or meeting rooms have the least. In this particular layout, most interior spaces are less exposed. This type of hierarchy echoes Oscar Newman's concept of defensible space that calls for creating a hierarchy of three zones for better natural surveillance. 
Table 1. Output of mean isovist areas for Building A and Building B.

\begin{tabular}{ccccc}
\hline Building Code & $\mathbf{N}$ & Mean & Std. Deviation & Std. Error Mean \\
\hline 1 & 73,904 & 2496.5836 & 1898.4972 & 6.98355 \\
2 & 14,360 & 463.9766 & 423.77735 & 3.53639 \\
\hline
\end{tabular}

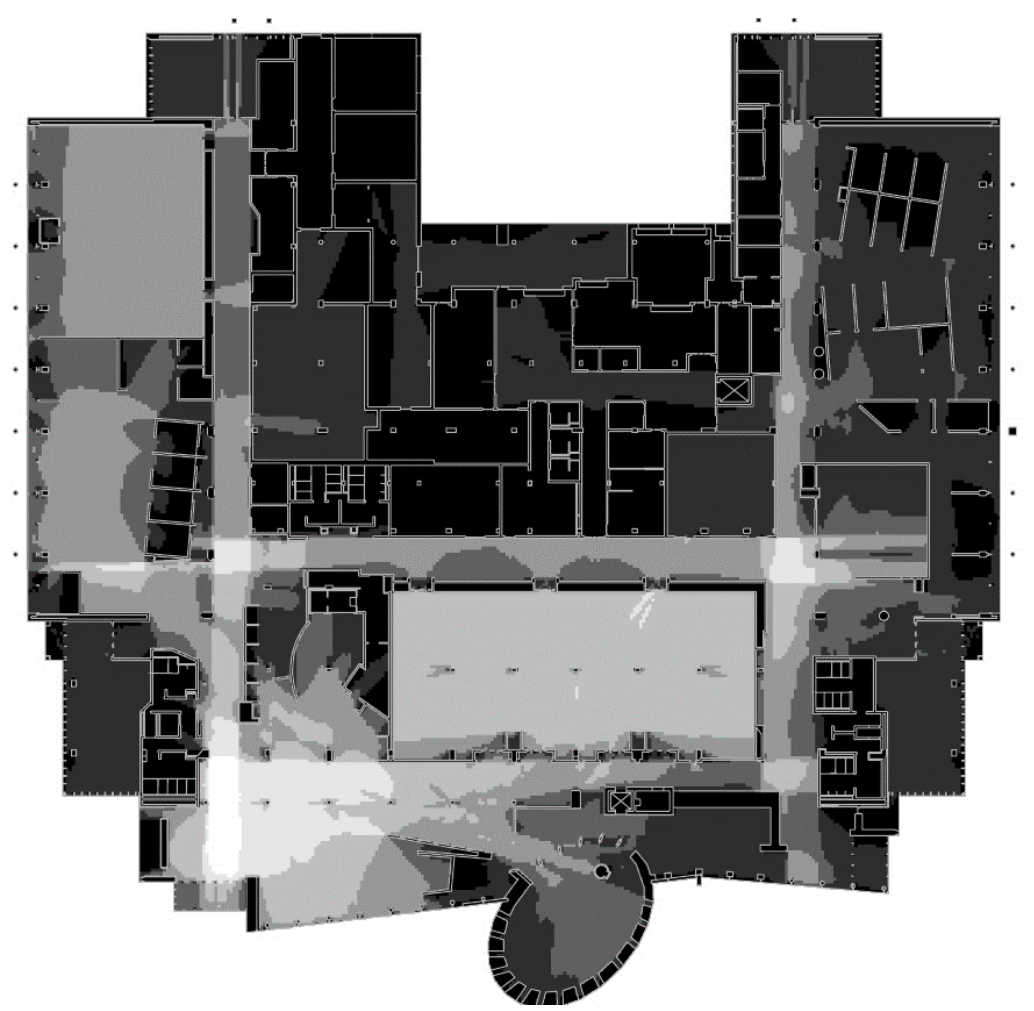

Figure 3. Shows the isovist area output for Building A ranging in color from white (high visibility area) to black (low visibility area).

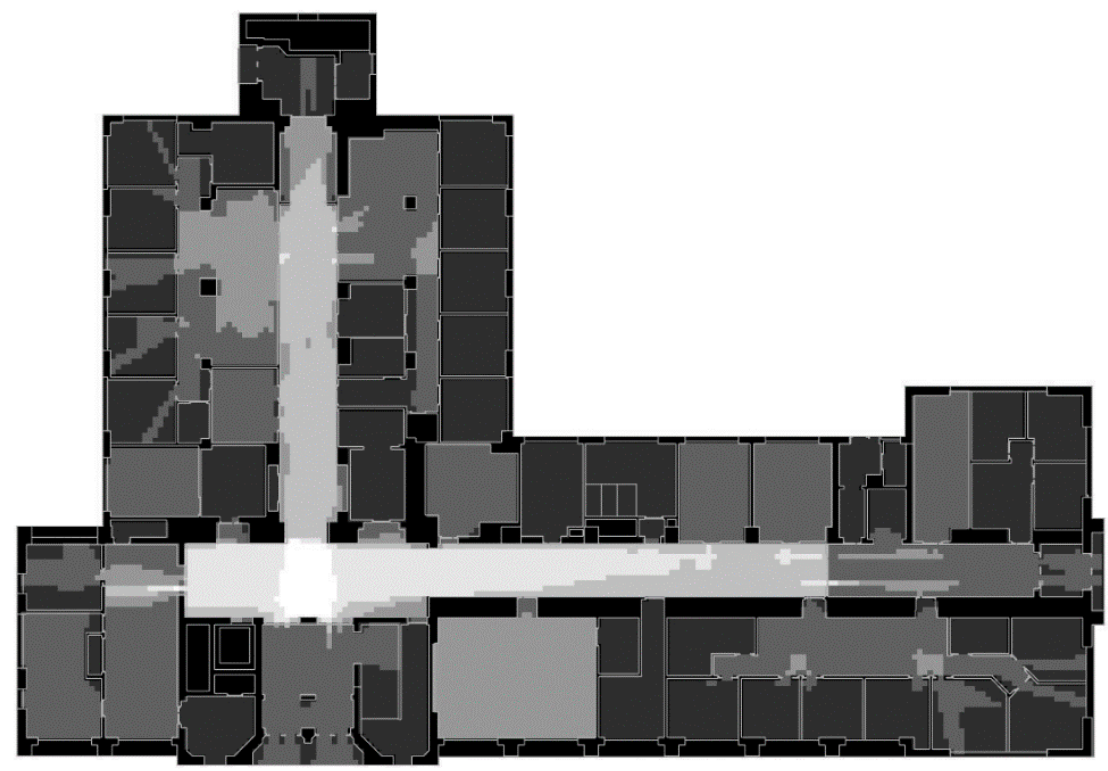

Figure 4. Shows the isovist area output for Building B ranging in color from white (high visibility area) to black (low visibility area). 
To further explain the phenomenon noted in the previous section, surveys were administered to police from six different agencies. When asked to list the visual attributes that make response more difficult, among the top concerns included large open areas, glass walls, blind corners, and windowless doors. The respondents also showed that it is important for the police to survey the area visually in order to process the situation. It makes sense then to suggest that a certain level of hierarchy in visual fields will help the police clear the building room by room safely. Field visits by the authors to both sites showed that executing Run or Hide during a teaching assignment could be challenging in Building A, since many of these spaces feel overly exposed.

\subsubsection{Finding 2}

When the two buildings were compared in terms of their integration and intelligibility, results showed that more than $80 \%$ of the spaces in Building A, are highly integrated making it a difficult task for someone to Hide, thus, increasing the probability of someone feeling trapped and exposed within the teaching space (see Figures 5 and 6).

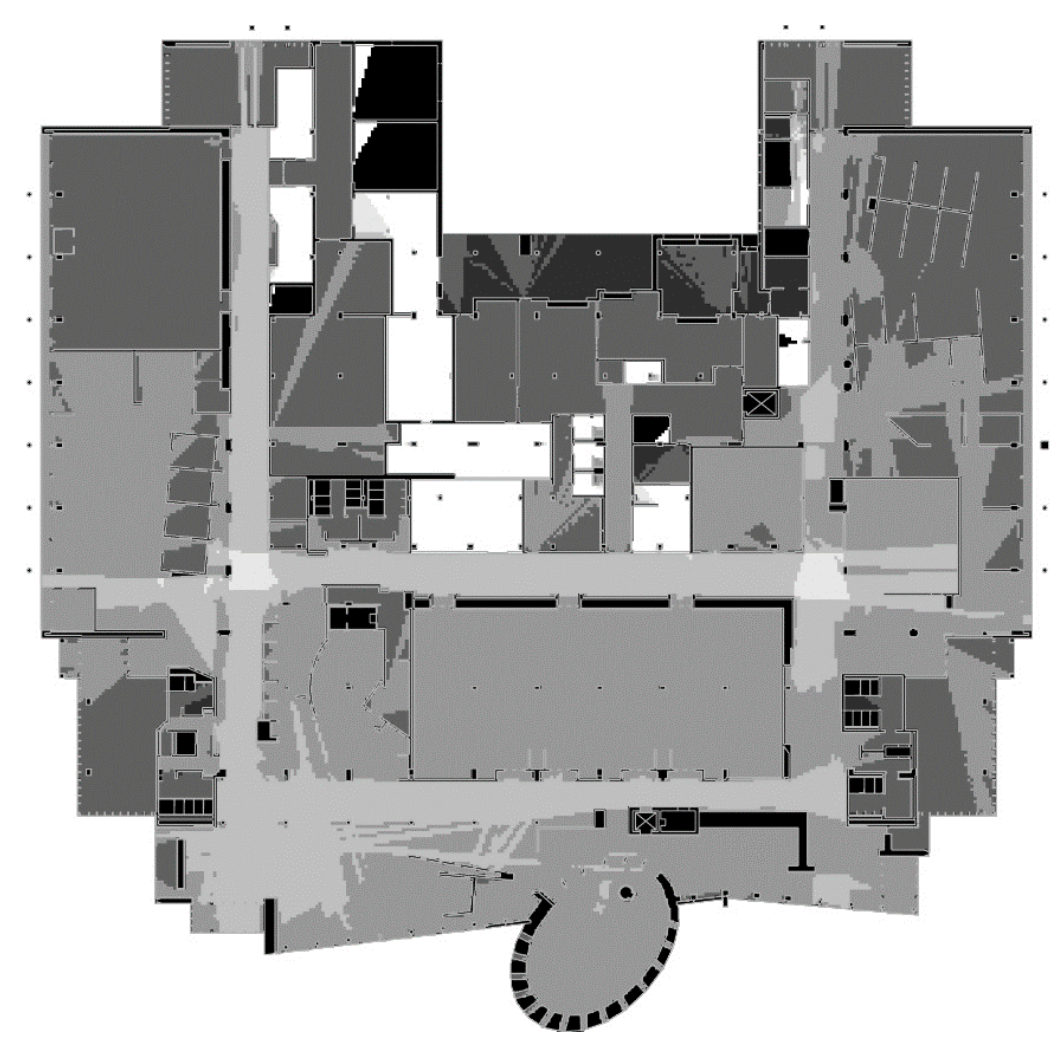

Figure 5. The visibility integration output of Building A, ranging in color from white (highly integrated isovists) to black (segregated isovists). 


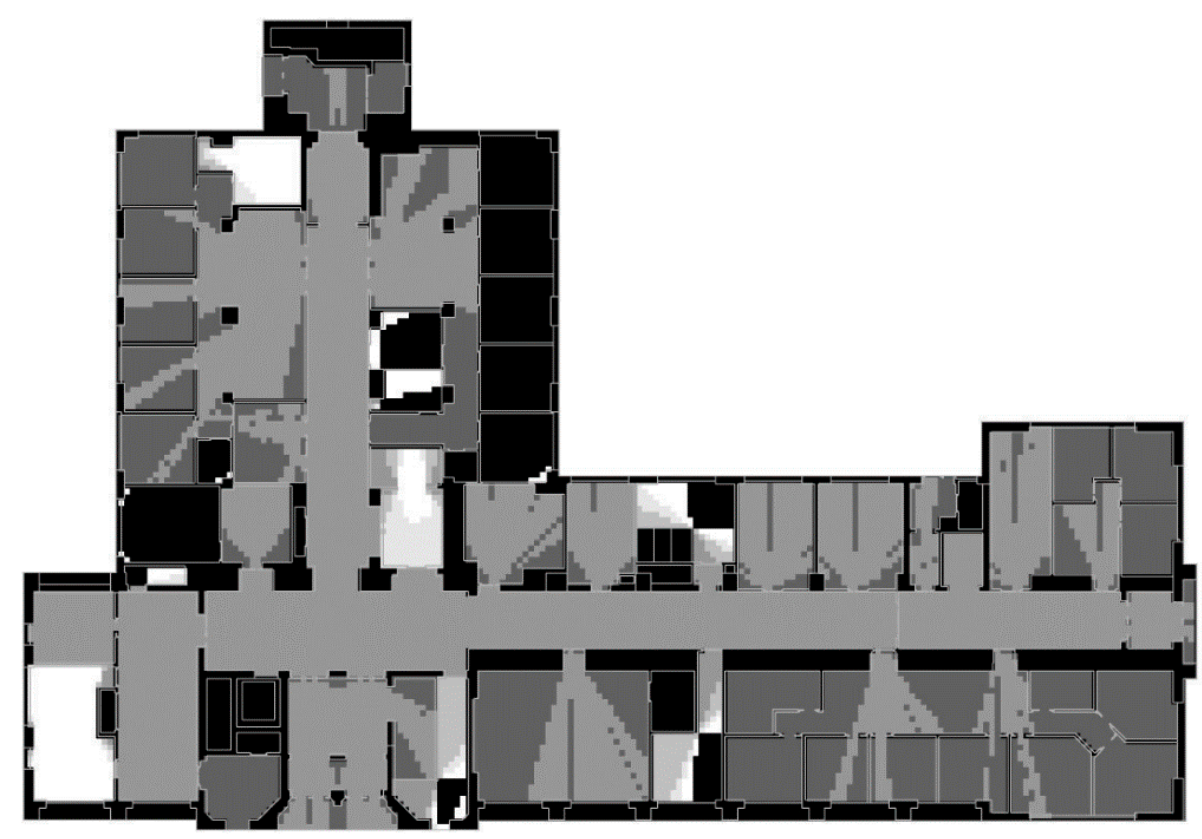

Figure 6. The visibility integration output of Building B, ranging in color from white (highly integrated isovists) to black (segregated isovists).

Results also showed that although both buildings were below the required level of intelligibility in floor plans, Building B had a better intelligibility value than Building A. This indicates that wayfinding in Building $B$ is expected to be easier than wayfinding in Building $A$.

To further explore the differences between the two floor plans in terms of executing Run, Hide, Fight; results from the surveys given to faculty members who were familiar with both buildings showed the following:

- There is an association between increased familiarity with a building and perceived preparedness against active shooting.

- The simplicity of the building layout and the ease of wayfinding supports the ability to execute Run and Hide.

- Respondents who are more familiar with the building feel more capable of executing Fight.

- Less than $22 \%$ of the respondents think that wayfinding in Building A is simple, while $80 \%$ of the respondents think that wayfinding in Building B is simple.

- Additionally, $9 \%$ of the respondents think that they are moderately prepared for an active shooter incident at Building A, while $60 \%$ think they are prepared in Building B.

- Approximately $35 \%$ of the respondents believe they can execute Run and Hide in Building A while about $70 \%$ of the respondents believe they can execute Run and Hide in Building B.

- The respondent's preparedness towards executing Fight varied significantly in the two buildings. $24 \%$ felt they can Fight in Building A while over 55\% felt they can Fight in Building B.

When a Wilcoxon Signed Test was performed to see measure whether respondents preparedness for Active Shooter Incidents was significantly different in those two buildings, results showed that the difference was statistically significant $(p=0.013)$. Additionally, Tables 2 and 3 display results from correlations that also show strong associations between their preparedness to execute Run, Hide, Fight and their perception of wayfinding and building layout in both buildings. For example, the more the respondents were familiar with Building $B$, the more they feel prepared to execute Fight. Respondents who reported that wayfinding in Building $B$ was simple indicated that they can Hide during an active shooting incident, however, the correlation was negative for Building A, indicating that wayfinding in Building A is not simple. Additionally, there was a strong association between the faculty's perception 
of the layout of Building B, and how that layout supports executing Run during an active shooting incident, the same correlation was negative for building A. All of the correlations reported in this section were significant at the 0.05 level.

Table 2. Output of correlated variables from survey respondents for Building A.

\begin{tabular}{|c|c|c|c|c|}
\hline Survey Questions & $\begin{array}{l}\text { Can You Execute } \\
\text { Run at Building A? }\end{array}$ & \multicolumn{2}{|c|}{$\begin{array}{c}\text { Can You Execute Hide at } \\
\text { Building A? }\end{array}$} & $\begin{array}{c}\text { Can You Execute } \\
\text { Fight at Building A? }\end{array}$ \\
\hline $\begin{array}{l}\text { How familiar are you with } \\
\text { Building A? }\end{array}$ & $\begin{array}{c}\text { Pearson } \\
\text { Correlation } \\
\text { Sig (2-tailed) } \\
\text { N }\end{array}$ & & & \\
\hline $\begin{array}{l}\text { Wayfinding at Building A } \\
\text { is simple }\end{array}$ & $\begin{array}{c}\text { Pearson } \\
\text { Correlation } \\
\text { Sig }(2 \text {-tailed }) \\
\text { N }\end{array}$ & $\begin{array}{c}-0.544^{*} \\
0.009 \\
22\end{array}$ & $\begin{array}{c}-0.535 * \\
0.01 \\
22\end{array}$ & $\begin{array}{c}-0.540 * \\
0.01 \\
22\end{array}$ \\
\hline $\begin{array}{l}\text { Do you think that Building } \\
\text { A Layout supports one's } \\
\text { preparedness against } \\
\text { active shooting incidents? }\end{array}$ & $\begin{array}{c}\text { Pearson } \\
\text { Correlation } \\
\text { Sig }(2 \text {-tailed }) \\
\text { N }\end{array}$ & $\begin{array}{c}-0.482 * \\
0.031 \\
22\end{array}$ & $\begin{array}{c}-0.468 * \\
0.037 \\
22\end{array}$ & $\begin{array}{c}-0.470 * \\
0.037 \\
22\end{array}$ \\
\hline
\end{tabular}

* Correlation is significant at the 0.05 level (2-tailed).

Table 3. Output of correlated variables from survey respondents for Building B.

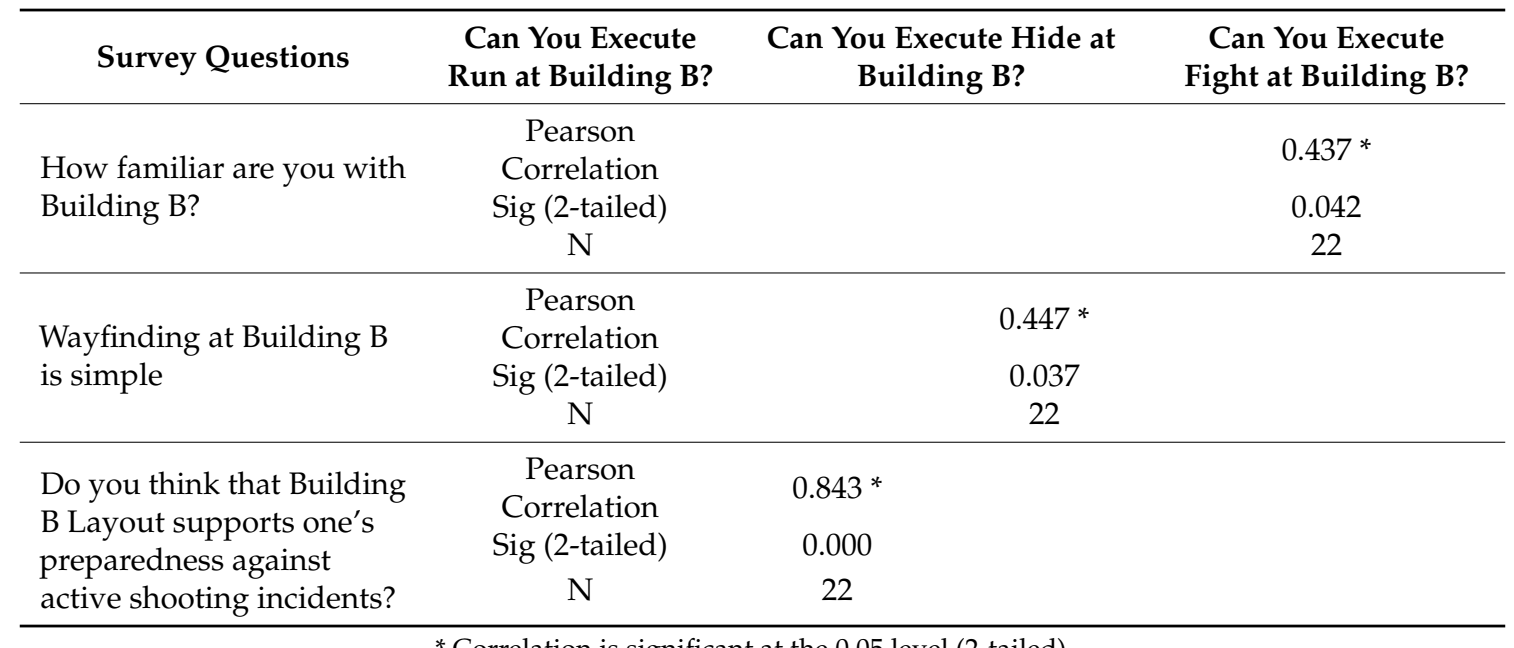

* Correlation is significant at the 0.05 level (2-tailed).

\section{Discussion and Policy Implications}

As evident in the literature review, studies showed that a shooter who intends to kill a large number of people spends more time planning specifically the amount of visual exposure in location selection. This implies some spatial decision-making by the shooter, indicating that a shooter's ability to see without being seen may be considered of high priority in planning stages, as witnessed from the note left behind by the Las Vegas shooter where calculations of visibility exposure were documented. The visibility simulation described and used in this pilot study gives the capacity to automate visibility calculations, and to highlight the areas that could be described as being potentially vulnerable in the event of a shooting. This knowledge identifies layouts in need of modification to mitigate risk. Modifications could be implemented practically, for example, through adjustment to the layout, the application of bullet-resistant film to windows, a simple installation of curtains to cover interior windows in classrooms, or the installation of gunshot detection technology. Perhaps the time is now to conduct visibility analyses on spaces, and to help improve security measures. 
Studies that looked at crime prevention measures in relation to crime at an urban level produced promising, predictive, inexpensive tools. Although similar tools were used to successfully measure certain behavioral outcomes, such as navigating through elementary schools [37], or wayfinding in hospitals [38], it might be useful to use these tools to address preparedness and response time inside buildings for active shooting prevention. This pilot study is the first of its kind to explore the same tools to assess preparedness from active shooting incidents. This leads the authors to propose the following implications:

- First, additional research is needed to analyze the perceptions of first responders of their level of preparedness when architectural and design features in a floor plan are presented to them ahead of time.

- Second, visibility-based simulations among architects and designers should be examined prior to implementation, to consider different scenarios that aid the users to execute Run, Hide, Fight.

- Third, amend existing codes and regulations to include guidelines that improve the user ability to execute Run, Hide, Fight.

\section{Conclusions}

Fundamental shifts in active shooter emergency training and preparedness have undoubtedly saved numerous lives in the last several years. While training continues to advance, the problem is far from resolved, but in fact, the number of casualties from active shooter incidents remains concerning. While authorities from various backgrounds are working to improve response and preparedness for this issue, experts agree that much more could be done to understand the nature of these rare events, and to maximize survival from active shooter attempts.

Though the survey sample size may be too small to offer statistical significance, the data may be most valuable in considering what questions are relevant to future research. Results from this pilot study showed how it is possible now to run simulations of building floorplans to see how the layout of the building impacts the user ability to execute Run, Hide, Fight as recommended by DHS. Also, these simulations can point to hotspots within the building that will increase awareness among first responders to the site.

Due to the short duration of the average incident, occupants will not likely have time to locate and review floor plans to determine how to evacuate a building at the time of a sudden active shooter threat. Therefore, occupants may have to rely on cognition and memory to recall the building layout and the means of egress. If training users to execute Run, will they know where to run? Is it easy to quickly evaluate the surroundings and make decisions in the moment? While faculties that have been teaching in the same classrooms or building may have increased familiarity with established evacuation routes, newer faculties and students who frequent a building for a class only twice a week may have less awareness of their surroundings. With visibility analysis, we can now measure such variables as egress, evacuation, and building logic. If the building layout is not intelligible, it may be difficult to understand how to quickly navigate evacuation routes when under duress. In existing buildings, we may introduce enhanced mapping and signage to promote wayfinding in an effort to mitigate this problem.

Possible applications of this research may improve or establish Emergency Action Plans for higher education, and provide police with hotspot analysis on the floor plans of campus buildings. The author identifies a need for architects and designers to take a closer look at how spaces are configured, to identify hotspots in buildings which may create opportunity for active shooters. In addition, recommendations may be proposed to update building codes. These codes are aimed at increasing passive design measures in prevention and deterrence techniques against active shooting, through the modification of existing buildings, as well as planning safer new buildings.

Author Contributions: Conceptualization, K.K.; Data curation, K.K. and L.N.; Formal analysis, K.K. and L.N.; Investigation, K.K.; Methodology, L.N.; Project administration, K.K.; Resources, K.K.; Software, L.N.; Supervision, 
L.N.; Visualization, K.K. and L.N.; Writing—original draft, K.K. and L.N.; Writing—review \& editing, K.K. and L.N.

Funding: This research received no external funding.

Conflicts of Interest: The authors declare no conflict of interest.

\section{References}

1. Blair, J.P.; Schweit, K.W. A Study of Active Shooter Incidents, 2000-2013. Texas State University and Federal Bureau of Investigation, U.S. Department of Justice: Washington, DC, USA. Available online: http:/ / www.fbi.gov / (accessed on 15 December 2017).

2. Schweit, K.W. Active Shooter Incidents in the United States in 2014 and 2015. Federal Bureau of Investigation, U.S. Department of Justice: Washington, DC, USA. Available online: https:/ / www.fbi.gov/file-repository/ activeshooterincidentsus_2014-2015.pdf (accessed on 15 April 2018).

3. Briggs, T.W.; Kennedy, W.G. Active Shooter: An Agent-based Model of Unarmed Resistance. In Proceedings of the 2016 Winter Simulation Conference, Arlington, VA, USA, 11-14 December 2016; IEEE Press: Piscataway, NJ, USA, 2016; pp. 3521-3531.

4. Peterson, J.; Sackrison, E.; Polland, A. Training students to respond to shootings on campus: Is it worth it? J. Threat. Assess. Manag. 2015, 2, 127-138. [CrossRef]

5. Police Executive Research Forum (PERF). The Police Response to Active Shooter Incidents; Police Executive Research Forum: Washington, DC, USA, 2014.

6. Ford, J.L.; Frei, S.S. Training for the Unthinkable: Examining Message Characteristics on Motivations to Engage in an Active-Shooter Response Video. Commun. Stud. 2016, 67, 438. [CrossRef]

7. Downs, S. Active shooter in educational facility. J. Emerg. Manag. 2015, 13, 303-326. [CrossRef] [PubMed]

8. Drysdale, D.A.; Modzeleski, W.; Simons, A.B. Campus Attacks: Targeted Violence Affecting Institutions of Higher Education. U.S. Secret Service, U.S. Department of Homeland Security: Washington, DC, USA; Office of Safe and Drug-Free Schools, U.S. Department of Education: Washington, DC, USA; Federal Bureau of Investigation, U.S. Department of Justice: Washington, DC, USA, 2010.

9. Preparedness Activities for High Threat Events Requires Additional Study. The InterAgency Board: Health, Medical and Responder Safety Subgroup: Arlington, VA, USA, April 2016. Available online: https:/ / www.interagencyboard.org/sites/default/files/publications/Preparedness\%20Activities\% 20for\%20HTE\%20Requires\%20Additional\%20Study.pdf (accessed on 15 April 2018).

10. Osborne, J.R.; Capellan, J.A. Examining active shooter events through the rational choice perspective and crime script analysis. Secur. J. 2015, 30, 880-902. [CrossRef]

11. Lang, J. Design Theory from an Environment and Behavior Perspective. In Advances in Environment, Behavior, and Design, 3rd ed.; Zube, E.H., Moore, G.T., Eds.; Springer: Boston, MA, USA, 1991; Volume 3, pp. 53-101, ISBN 978-1-4684-5816-9.

12. Steenbeek, W.; Weisburd, D. Where the action is in crime? An examination of variability of crime across different spatial units in the Hague, 2001-2009. J. Quant. Criminol. 2016, 32, 449-469. [CrossRef]

13. Hollis, M.E.; Felson, M.; Welsh, B.C. The capable guardian in routine activities theory: A theoretical and conceptual reappraisal. Crime Prev. Community Saf. 2013, 15, 65-79. [CrossRef]

14. Newman, O. Defensible Space: Crime Prevention through Urban Design; Collier Books: New York, NY, USA, 1973; ISBN 978-0020007500.

15. Jacobs, J. The Death and Life of Great American Cities; Random House: New York, NY, USA, 1961; ISBN 978-0679741954.

16. Camp, G.M. Nothing to Lose: A Study of Bank Robberies in America. Ph.D. Thesis, Yale University, New Haven, CT, USA, 1968.

17. Archae, J.C. The Use of Architectural Props in the Conduct of Criminal Acts. J. Archit. Plan. Res. 1985, 2, 245-259.

18. Nubani, L.N. Targets for Crime: Measuring the Spatial and Visual Attributes of Crime Locations Using Space Syntax. Ph.D. Thesis, University of Michigan, Ann Arbor, MI, USA, 2006.

19. Nubani, L.; Wineman, J. The Role of Space Syntax in Identifying the Relationship between Space and Crime. In Proceedings of the Fifth International Space Syntax Conference, Delft, The Netherlands, 13-17 June 2005.

20. Lynch, K. The Image of the City; The MIT Press: Boston, MA, USA, 1960; ISBN 0262620014. 
21. Tao, Y.; Gou, Z.; Lau, S.S.; Lu, Y.; Fu, J. Legibility of floor plans and wayfinding satisfaction of residents in care and attention homes in Hong Kong. Australas. J. Ageing 2018. [CrossRef] [PubMed]

22. Haq, S.; Luo, Y. Space syntax in healthcare facilities research: A review. Health Environ. Res. Des. J. 2012, 5, 98-117. [CrossRef]

23. Fox, J.A.; Savage, J. An Examination of Changes on College Campuses Following Virginia Tech. Am. Behav. Sci. 2009, 52, 1465-1485. [CrossRef]

24. Kelly, R.W. Active Shooter: Recommendations and Analysis for Risk Mitigation 2012 Edition. New York City Police Department: New York, NY, USA, 2012. Available online: http:/ /www.nyc.gov/html/nypd/ downloads/pdf/counterterrorism/ActiveShooter2012Edition.pdf (accessed on 15 April 2018).

25. Levin, J.; Madfis, E. Mass Murder at School and Cumulative Strain: A Sequential Model. Am. Behav. Sci. 2009, 52, 1227-1245. [CrossRef]

26. Capellan, J.A. Lone Wolf Terrorist or Deranged Shooter? A Study of Ideological Active Shooter Events in the United States, 1970-2014. Stud. Confl. Terror. 2015, 38, 395-413. [CrossRef]

27. Hanna, J.; Almasy, S.; McKirdy, E.; Rehbein, M. Las Vegas Shooter Left Behind Calculations for Targeting Crowd. CNN, 20 October 2017.

28. Green, D.D. Exploring Police Active Shooter Preparedness in Michigan: A Grounded Study of Police Preparedness to Active Shooter Incidents, Developing a Normative Model. Ph.D. Thesis, Western Michigan University, Kalamazoo, MI, USA, 2013.

29. Murgado, A. Quicker Response to Active Shooters. Police Magazine. 16 October 2013. Available online: http:/ / www.policemag.com/channel/patrol/articles/2013/10/quicker-response-to-active-shooters.aspx (accessed on 15 April 2018).

30. Pignatelli, D.A. Exploring Ohio Police Preparedness for Active Shooter Incidents in Public Schools. Ph.D. Thesis, Northcentral University, Scottsdale, AZ, USA, 2010.

31. Hyderkhan, S.M. The Active Shooter Response Training Manual; CRC Press/Taylor and Francis Group: Boca Raton, FL, USA, 2014.

32. Nubani, L.; Puryear, A.; Kellom, K. Measuring the effect of visual exposure and saliency of museum exhibits on visitors' level of contact and engagement. Behav. Sci. 2018, 8, 100. [CrossRef] [PubMed]

33. Nubani, L. Evaluating workplace constructs using computerized techniques of space syntax. In Building Performance Evaluation: From Delivery Process to Life Cycle Phases; Preiser, W., Hardy, A., Schramm, U., Eds.; Springer: Cham, Switzerland, 2018; pp. 141-154.

34. Turner, A. Depthmap: A program to perform visibility graph analysis. In Proceedings of the Third International Space Syntax Symposium, Atlanta, GA, USA, 7-11 May 2001; Peponis, J., Wineman, J., Bafna, S., Eds.; pp. 31.1-31.9.

35. Hillier, B.; Sahbaz, O. High resolution analysis of crime patterns in urban street networks. In Proceedings of the Fifth International Space Syntax Conference, Delft, The Netherlands, 13-17 June 2005.

36. Rashid, M.; Zimring, C.; Wineman, J.; Flaningam, T.; Nubani, L.; Hammash, R. The effects of spatial behaviors and layout attributes on individuals' perception of psychosocial constructs in offices. In Proceedings of the Fifth International Space Syntax Conference, Delft, The Netherlands, 13-17 June 2005.

37. Lee, S.; Ha, M. The Effects of Visibility on Fear of Crime in Schools' Interior Environments. J. Asian Archit. Build. Eng. 2016, 15, 527-534. [CrossRef]

38. Haq, S.; Zimring, C. Just Down the Road A Piece: The Development of Topological Knowledge of Building Layouts. Environ. Behav. 2003, 35, 132-160. [CrossRef]

(C) 2018 by the authors. Licensee MDPI, Basel, Switzerland. This article is an open access article distributed under the terms and conditions of the Creative Commons Attribution (CC BY) license (http://creativecommons.org/licenses/by/4.0/). 